\title{
Comparison of Anthropometric and Body Composition Characteristics in Children and Adolescents of Asian Indian Origin: Santiniketan Maturity Study
}

\author{
Arnab Ghosh \\ Biomedical Research Laboratory, Department of Anthropology, Visva Bharati University, Santiniketan, West Bengal, India
}

Running title: Body composition during maturity

\begin{abstract}
Objective: The present cross-sectional study was aimed to investigate the anthropometry and body composition characteristics during puberty and adolescence in children and adolescents of Asian Indian origin. Methods: A total of 305 healthy children and adolescents (152 males and 153 females) aged 9 to 20 years took part in the study. The study population was divided into four age groups: Group I= 9-11 years; Group II= 12-14 years; Group III=15-17 years and Group IV= 17 years and above. Height, weight, circumferences of mid upper arm, waist and hip as well as skinfold thickness were collected using standard techniques. Body composition measures namely percentage of body fat, fat mass fat free mass, arm muscle circumference, arm muscle area and arm fat area were also considered. Results: One way analysis of variance revealed that there were significant $(p<0.001)$ age group differences for mean values of anthropometric and body composition characteristics. Percentage of body fat showed significant (p<0.001) sex difference in the mean value for all four age groups. It was observed that for both male and female \%BF, FM, FFM, AMC, AMA and AFA had significantly higher mean values in groups with presence of secondary sexual characteristics (for male) and menarche (for female) compared to those who did not attain the same. There existed significant $(p<0.01)$ sex difference for biological maturity status by age groups and sex. Conclusion: Greater fat mass in females and greater muscle mass in males could be attributed to the onset of differential sex steroids during puberty.
\end{abstract}

Keywords: body composition, adolescence, puberty, hormones, Asian Indians

\section{Introduction}

Anthropometric measures are especially important during puberty and adolescence because it allows the monitoring and evaluation of hormone-mediated changes in growth and maturation during these periods (Malina and Bouchard, 1991). Adolescence is characterized by the onset of major maturational events principally the spurt in somatic growth and the accompanying appearance of secondary sexual characteristics, menarche and spermarche. There is a marked variation in the timing of these maturational changes, so that growth evaluation based exclusively on chronological age may be inaccurate, particularly when applied to individual maturity (WHO, 1995).

There are a number of body parameter have been studied for tracing the sex variation i.e. changes in the body composition at the prepubertal and pubertal stage in boys and girls (Kirgengast and Steiner, 2001; Maynard et al., 2001; Forwood et al., 2004; Arabi et al., 2004). In girls the rate of increase in cell number is more or less constant until maturity is achieved, on contrary in boys there is an acceleration starting at about age 11 (Tanner, 1975). Males show a greater increase in the fat free mass (FFM) where as females show an increase in the fat mass (FM) during the pubertal and post pubertal stage. All of these events take place due to steroid and insulin like growth factor 1 (IGF1) and leptin (Friedman and Halaas, 1989; Garnett et al., 2004; Ruhl et al., 2004).
Superimposed on the more gradual age related changes in anthropometric measurements occurs during sexual development. This association is more pronouncedly observed between sexual development and fat folds thickness as well as for mid upper arm circumference (MUAC). The onset of puberty changes the rate of subcutaneous fat deposition and fat distribution as measured by skinfold thickness (Martin et al., 1993; Gasser et al., 1993; Deurenberg et al., 1990; Samsudin, 1990; Garcia Liop et al., 1990). It was observed that the body mass index (BMI) throughout the childhood was almost similar for boys and girls although significantly lower value was observed at ages 12-13 years (Maynard et al., 2001). Maximum BMI was a strong predictor for adult BMI and in females, a strong predictor of adulthood total body fat (TBF) and percentage of body fat (\%BF) (Malina and Bouchard, 1991). Maximum BMI on the other was closely related to maximum BMI velocity in boys and girls (Guo et al., 2000). In US adolescence, it was also observed that the mean total body weight (TBW) and fat free mass increased from adolescence years to mid adulthood with girls had higher mean of TBF and \%BF than boys at each age group (Chumlea et al. 2002).

In adolescents body fatness has been associated with socioeconomic status (Booth et al., 1999) and changes in body composition may depend on location of residence or habitat (Dollman and Pilgrim, 2005). Furthermore, study to investigate changes in the obesity parameters during maturity have had shown that total body fat (TBF), FFM, BMI, sum of two $\left(\mathrm{SF}_{2}\right)$ and sum of six $\left(\mathrm{SF}_{6}\right)$ skinfolds 


\section{International Journal of Science and Research (IJSR) \\ ISSN (Online): 2319-7064 \\ Index Copernicus Value (2013): 6.14 | Impact Factor (2015): 6.391}

thickness had a strong divergence between boys and girls over the time and that such divergence was more marked among the blacks than among the non-blacks (Dai et al., 2002). This indicates the ethnic and region specific information on anthropometry and body composition during normal developmental phases is utmost required (WHO, 1995).

Keeping this view in mind, the present cross-sectional study was aimed to examine the anthropometry and body composition characteristics during puberty and adolescence in children and adolescents of Asian Indian origin.

\section{Participants and Methods}

The present school based cross-sectional study was conducted during the period of March to May 2008. A total of 305 healthy children and adolescents (152 males and 153 females) aged 9 to 20 years took part in the study. All participants were recruited from the Visva Bharati University School at Santiniketan, India. The age was ascertained from school registrar. The study population was divided into four age groups: Group $\mathrm{I}=9-11$ years; Group $\mathrm{II}=12-14$ years; Group $\mathrm{III}=15-17$ years and Group $\mathrm{IV}=17$ years and above. All subjects were belong to Bengalee population and were inhabitants of the Santiniketan-Bolpur area, Birbhum district, West Bengal, India (the district 'Birbhum' lies in between $23^{0} 32$ ' $30^{\prime}$ ' and $24^{0} 35^{\prime} 00^{\prime}$ ' north latitude and $88^{\circ} 10^{\prime} 40^{\prime \prime}$ and $87^{\circ} 05^{\prime} 25^{\prime}$ ' east longitude). The socio-economic status of these subjects was moderate to average as assessed by their materialistic possession.

Height, weight, circumferences of mid upper arm (MUAC), waist (MWC) and hip as well as skinfold thickness at biceps, triceps, subscapular and suprailiac were collected using standard techniques (Lohman et al. 1988). Height and weight of lightly clothed subjects were measured to the nearest $0.1 \mathrm{~cm}$ and $0.1 \mathrm{~kg}$ respectively. Skinfold thickness was measured on the left side of the body to the nearest 0.2 mm using a Holtain skinfold caliper (Holtain Corporation, UK). Circumferences were measured with an inelastic tape to the nearest $0.1 \mathrm{~cm}$. Percentage of body fat $(\% \mathrm{BF})$ and body mass index (BMI) were measured using an Omron body fat analyser (Omron Corporation, Tokyo, Japan). The validity of analyser was checked periodically by calculating BMI separately using standard equation.

Fat mass (FM) was then calculated. The following equations were used:

$\mathrm{FM}(\mathrm{kg})=(\% \mathrm{BF} / 100) \times \mathrm{W}$ Weight $(\mathrm{kg})$

Fat free mass (FFM) was calculated as:

FFM $(k g)=$ Weight $(k g)-$ FM $(k g)$

Arm muscle circumference (AMC) and Arm muscle area (AMA) were derived using the standard equation (Burr et al. 1984).

AMC $(\mathrm{cm})=$ MUAC $(\mathrm{cm})-\pi($ Triceps skinfold in $\mathrm{cm})$

$\operatorname{AMA}\left(\mathrm{cm}^{2}\right)=\operatorname{AMC}\left(\mathrm{cm}^{2}\right) / 4 \pi$

Arm fat area (AFA) was calculated using the following equation (Paeratakul et al. 1999).

AFA $\left(\mathrm{cm}^{2}\right)=($ Triceps in $\mathrm{cm} x$ MUAC in $\mathrm{cm})-(\pi \mathrm{x}$ Triceps in $\left.\mathrm{cm}^{2}\right) / 4$
$\mathrm{SF}_{4}$ (sum of four skinfolds in $\left.\mathrm{mm}\right)=($ Biceps + Triceps + Subscapular+ Suprailliac)

Using a pre-designed schedule, information on I) personal details (i.e. name, age, marital status of parents, age at puberty, etc.) as well as II) socioeconomic characteristics (i.e. type of family, family size, monthly family expenditure, source of drinking water, occupation, education etc.) were obtained from participants. The schedule was checked for competence using a subset $(n=30)$ of the participants prior to actual commencement of the study.

Descriptive statistics such as mean and standard deviation were undertaken separately for four groups. Comparison of groups for variables was done using analysis of variance (ANOVA). Unpaired t-test by sex was undertaken to compare individual characteristics for anthropometry and body composition during sexual maturation. Chi-square test was also computed to asses whether there was any sex difference for biological maturational status of the study population.

All statistical analyses were performed using the SPSS (PC+ version 10). A p value of $<0.05$ (two tailed) was considered as significant.

\section{Results}

The Socioeconomic characteristic of the study population is presented in Table 1. Most of the subjects (60.7\%) were belonged to nuclear family with $76.4 \%$ subjects had own house and $8.5 \%$ participants were living the hostel. A total of 305 subjects took part in the study, out of which 152 were male (mean age $=14.3$ years, $\mathrm{SD}=4.0$ ) and 153 were female (mean age $=14.6$ years, $\mathrm{SD}=5.0$ ). The mean menarcheal age for female participants was 12.73 years ( $\mathrm{SD}=1.5$ years).

The subjects were categorized into four age groups. The mean and SD of anthropometric and body composition characteristics by age groups and sex are presented in Table 2. One way ANOVA revealed that there were significant $(p<0.001)$ age group differences for mean values of anthropometric and body composition characteristics. No sex difference for mean age within each age group category vindicated the age matched nature of sample in the study. Percentage of body fat showed significant $(p<0.001)$ sex difference in the mean value for all four age groups. Both $\mathrm{SF}_{4}$ and AFA also revealed significant $(\mathrm{p}<0.001)$ sex difference in the mean values for all four age groups except Group I (9-11 years). No sex difference across the age groups was observed for FFM.

Comparison of body composition characteristics by maturity status and by sex are presented in the Table 3. Overall, 44\% male participants had developed sign of secondary sexual characteristics compared to $63 \%$ female who had experienced menarche at the time of examination. It was also observed for both male and female that \%BF, FM, FFM, AMC, AMA and AFA had significantly higher mean values in groups with secondary sexual characteristics (for male) and menarche (for female) compared to those who did not attain the same. 


\section{International Journal of Science and Research (IJSR) \\ ISSN (Online): 2319-7064 \\ Index Copernicus Value (2013): 6.14 | Impact Factor (2015): 6.391}

The biological maturation status of participants by the four age groups is presented in Figure 1. It was observed that no sign of appearance of secondary sexual characteristics in boys was evident in the age group of 9-11 years with only five girls had experienced menarche in the same category. Furthermore, 5 boys with secondary sexual characteristic and 25 girls with menarche were evident in the age group of 12-14 years. Chi-square test revealed there existed significant $(\mathrm{p}<0.01)$ sex difference for biological maturity status in male and female across the age groups (result was not shown).

\section{Discussion}

The present investigation was aimed to compare anthropometric and body composition characteristics in children and adolescence of Asian Indian origin. Throughout the development of evaluating body composition and maturation during puberty and adolescence, various methods to assessing body composition have had evolved. However, anthropometry, till date, is universally acceptable, inexpensive and non invasive method to assess proportion and composition of human body during normal growth and development (WHO, 1995). Body composition during puberty and adolescence is a marker of physiological changes that occur during the pubertal period of growth and maturation and therefore provides key information regarding current and future health of children and adolescents. During puberty, the components of body composition all increases with considerable sexual dimorphism does exist (Roger et al. 2003). The physiological changes occur during puberty and adolescence includes rapid increases in body size, hormonal fluctuations (predominantly sex hormones), marked changes in body composition and the timing of various maturational landmarks (e.g. menarche in girls) is strongly related with body composition (Roger et al. 2003).

A number of studies have had examined the changes in body composition characteristics and fat topography during puberty and adolescence. After puberty male shows greater increase in FFM whereas female shows greater increase in FM and increase prevalence of obesity (Booth et al.1999; Kirgengast and Steiner 2001; Maynard et al. 2001; Sampei et al. 2003; Forwood et al. 2004).

In the present study, it was observed that almost all the anthropometric (i.e. Height, Weight, BMI, $\mathrm{SF}_{4}, \mathrm{WHR}$ ) and body compositional variables (\%BF, FM, FFM, AMC, AMA and AFA) had increased gradually across the age groups and sex. However, for $\mathrm{SF}_{4}$, only girls showed significant increasing trend across the age groups. This could be due to greater influence of female sex hormone on centripetal fat depots (Siervogel et al. 2000). In Fels longitudinal study, the level of TBF was increased at a fairly constant rate from a mean of approximately $5.5 \mathrm{~kg}$ at 8 years of age to about $15 \mathrm{~kg}$ at 16 years (Siervogel et al. 1991; 2000). It was also observed that FFM increased in girls until around the age of 15 years and then remains relatively unchanged where as in boys FFM was increased steadily between the ages of 8 and 18 years. In our study, it was observed that until 12 years, there was little or no sex difference for anthropometric and body composition measures and therefore reinforced the fat that before the onset of puberty, the variation in the anthropometric parameters for boys and girls are relatively small (Jurimae and Jurimae, 2001). Puberty starts rather earlier in girls compare to boys and is expressed as rapid increases in different anthropometric and body composition measures (Roemmich and Rogel, 1995; Rolland-Cachera, 1995; Siervogel et al. 2000). In the present study also, it was observed that there was not a single boy who had early sign to develop either moustache or beard or had experienced voice change in the age group of 9-11 years. In contrary, five girls had been found with menarche in the same age group. Furthermore, in the age group of 12-14 years also, girls had outnumbered boys to develop early sign of maturity.

There were significant differences for body composition measures in subjects with or without sign to develop beard or moustache or voice change (for males) and onset of menarche (for females) means onset of secondary sexual characteristics had considerable impact on body composition measures. It is noteworthy to mention that female subjects with menarche had greater \%BF, FM and AFA compare to male subjects even with sign of secondary sexual characteristics. On the other, male subjects with sign of secondary sexual characteristics had greater amount of FFM, AMC and AMA compare to female participants who had already experienced the event menarche. This sex differences in fat and muscle mass could be attributed to the onset of differential sex steroids during puberty.

However, the main limitation of the study was that it was performed on relatively small sample size and therefore is not representative of the Asian Indian children and adolescence. Owing to vast ethnic and cultural heterogeneity in the Indian population, it is imperative to study other ethnic groups to see if the trend observed also exists among them. Results obtained from such studies could be utilized to define body composition in Asian Indian children and adolescence. At the same time, in order to comprehend body composition changes during adolescence, carefully conducted prospective studies are required to establish limits and guidelines for Asian Indian children and adolescence. Moreover, investigation should be undertaken among the 'Indian Diaspora' worldwide to elucidate if they (migrant Indian children and adolescence) also show a similar trend to that of sedentes in India or native population of the respective counties. Such studies would generate valuable information on the nature-nurture interaction involved in body composition.

\section{Conflict of Interest}

There is no conflict of interest for authorship as well as funding is concerned. This is to certify that we did not receive any fund from any agency either in Indian and abroad to do this work. Author is grateful to the participants for their sincere cooperation during data collection. AG was responsible for the study design, analyses and final version of the manuscript

\section{References}

[1] Arabi, A., Tamim, H., Nabulsi, M., Maalouf, J., Khalife, J., Choucair, M., Vieth, R., EL-Hajj, G., 2004. Sex

\section{Volume 5 Issue 4, April 2016}




\section{International Journal of Science and Research (IJSR) \\ ISSN (Online): 2319-7064 \\ Index Copernicus Value (2013): 6.14 | Impact Factor (2015): 6.391}

differences in the effect of body composition variables on bone mass in healthy children and adolescents. Am. J. Clin. Nutr.80, 1428-1435.

[2] Banerjee, I., Ghia, N., Bandhopadhyay, S., Saiyad, H.N., Mukherjee, D., 2005. Body Mass Index in adolescents. Indian. Pedtr. 42; 262-267.

[3] Booth, M. L., Macaskill, P., Lazarus, R., Baur, L.A., 1999. Socioeconomic distribution of measures of body fatness among children and adolescents in New South Wales, Australia. Int. Obes. Relat. Metab. Disord.23, 456-462.

[4] Burr, M.L., Phillips, K.M., 1984. Anthropometric norms in the elderly. Br J Nutr. 51, 165-169.

[5] Chumlea, W.C., Guo, S.S., Kuczmarski, R.J., Flegal, K.M., Johnson, C.L., Heymsfield, S.B., Lukaski, H.C., Friedl, K., Hubbard, V.S., 2002. Body composition estimates from NHANES- III bioelectrical impedance data. Int J Obes Relat Metab Disord. 26, 1596-1609.

[6] Dai, S., Labarthe, D.R., Grunbaum, J.A., Harrist R.B., Mueller, W.H., 2002. Longitudinal analysis of changes in indices of obesity from age 8 years to age 18 years: Project Heart Beat. Am. J. Epidemiol. 156,720-729.

[7] Deurenberg, P., Pieters, J.J., Hautvast, J.G., 1990. The assessment of the body fat percentage by skinfold thickness measurements in childhood and young adolescence. Br. J. Nutr. 63, 293-303.

[8] Dollman, J., Pilgrim, A., 2005. Changes in body composition between 1997 and 2002 among South Australian children: Influences of socioeconomic status and location of residence. Aust. N. Z. J. Public Health. 29, 166-170.

[9] Forwood, M. R.,Bailey, D.A., Beck TJ.,Mirwald RL.,l.,Baxter-Jones, AD.,Uusi-Rasi, K., 2004. Sexual dimorphism of the femoral neck during the adolescent growth spurt: A structural analysis. Bone 35, 973-998.

[10] Friedman, J. M., Halaas, J.L., 1998. Leptin and the regulation of body weight in mammals. Nature 395, 763-770.

[11] Garcia Llop, L.A., Ramada Benedito, A., RodriguezEstecha, P., 1990. Relationship between sexual maturation and subcutaneous fat. Anales Espanoles de Pediatria 33, 349-353.

[12] Garnett, S. P., Hogler W., Blades, B., Baur, LA., Peat, J., Lee, J., Cowell, CT., 2004. Relation between hormones and body composition, including bone, in prepubertal children. Am. J. Clin. Nutr. 80, 966-972.

[13] Gasser, T., Ziegler, P., Kneip, A., Prader, A., Molinari, L., Largo, R.H., 1993. The dynamics of growth of weight, circumferences and skinfolds in distance, velocity and acceleration. Ann. Hum. Biol. 20, 239-259.

[14] Guo, S.S., Huang, C., Maynard, L.M., Demerath, E., Towne, B., Chumlea, W.C., Siervogel, R.M., 2000. Body mass index during childhood, adolescence and young adulthood in relation to adult overweight and adiposity: the Fels Longitudinal Study. Int. J. Obes. 24, 1628-1635.

[15] Jürimäe, T., Jürimäe, J., 2001. Growth, Physical Activity and Motor Development in Prepubertal Children. CRC Press, Boca Raton.

[16] Kirgengast, S., Steiner, V., 2001. Sexual dimorphism in body composition, weight status, and growth in prepubertal school children from rural areas of eastern Austria. Coll. Antropol.25, 21-30.
[17]Lohman, T.G., Roche, A.F., Martorell, R., 1988 Anthropometric Standardisation Reference Manual. Champaign, IL: Human Kinetics Books.

[18] Malina, R.M., Bouchard, C., 1991. Growth, maturation and physical activity. Champaign, I.L., Human Kinetics Books.

[19] Martinez, E., Devesa, M., Bacallao, J., Amador, M., 1993. Subscapular/triceps index: percentile values in Cuban children and adolescents. Archivos Latinoamericanos de Nutricion. 43, 199-203.

[20] Maynard, L. M., Wisemandle, W., Roche, A, F., Chumlea, W.C., Guo, S.S., Siervogel, R.M., 2001. Childhood body composition in relation to body mass index. Pediatrics. 107, 344-350.

[21] Nguyen, T.V., Maynard, L.M., Towne, B., Roche, A.F., Wisemandle, W.A., Li, J., Guo, S.S., Chumlea W.C., Siervogel, R.M., 2001.Sex differences in bone mass acquisition during growth: the Fels Longitudinal Study. J Clin Densitom .4, 147- 157.

[22] Paeratakul, S., Adair, A.S., Zhai, F., Ge, K., Popkin, B.M., 1999. Sex difference in measures of body fatness and the possible difference in the effect of dietary fat on body fatness in men and women. Eu. J. Clin. Nutr. 53, 865-871.

[23] Roemmich, J.N., Rogel, A.D., 1995. Physiology of growth and development: Its relationship to performance in the young athlete. Clin. Nutr. Sports Med.14, 483-502.

[24] Roger, M., Siervogel, E.W., Demerath, C.S., Karen, E., Remsberg, W., Cameron Chumlea, S.S., Stefan, A., Czerwinski, B.T., 2003. Puberty and Body Composition. Horm Res. 60 (suppl 1), 36-45.

[25] Rolland- Cachera, M.F., 1995. Prediction of adult body composition from infant and child measurements in the body composition techniques in health and disease. Davis, P.S., Cole, T.J., eds. Cambridge University Press, Cambridge . 100-105.

[26] Ruhl, C. E., Everhart, J.E., Ding, J.,Goodpaster B.H., Kanaya, A.M.,Simonsick E.M., Tylavsky F.A., Harris, T.B., 2004. Health, aging, and body composition study: Serum leptin concentrations and body adipose measures in older black and white adults. Am. J. Clin.Nutr. 80, 576-583.

[27] Sampei, M.A., Novo N.F., Juliano, Y., Colugnati, F.A.B., Sigulem, D.M., 2003. Anthropometry and body composition in ethnic Japanese and Caucasian adolescent girls: considerations on ethnicity and menarche. Int. J. Obes. 27, 1114-1120.

[28] Samsudin., 1990. The age of menarche as related to physical growth of junior high school girls in Jakarta. Pditr. Indo.30, 254-260.

[29] Siervogel, R.M., Roche, A.F., Guo, S.M., Mukherjee, D., Chumlea, W.C., 1991. Patterns of change in weight/stature ${ }^{2}$ from 2 to 18 years: Findings from longterm serial data for children in the Fels Longitudinal Growth Study. Int. J. Obes.15, 479-485.

[30] Siervogel, R.M., Maynard, L.M., Wisemandle, W.A., Roche, A.F., Guo, S.S., Chumlea, W.C., Towne, B., 2000. Annual changes in total body fat (TBF) and fat free mass (FFM) in children from 8 to 18 years in relation to changes in body mass index (BMI). The Fels Longitudinal Study. Ann. NY. Acad. Sci. 904, 420-423. 


\section{International Journal of Science and Research (IJSR) \\ ISSN (Online): 2319-7064 \\ Index Copernicus Value (2013): 6.14 | Impact Factor (2015): 6.391}

[31] Tanner, J.M., 1978. Foetus into man: physical growth from conception to maturity.

[32] World Health Organization. 1995. Physical Status: the Use and Interpretation of Anthropometry. Report of a
WHO Expert Committee. WHO Technical Report Series 854. Geneva: WHO.

Table 1: Socio-economic characteristics of the study population $(n=305)$

\begin{tabular}{|l|c|}
\hline Characteristics & Percentage (\%) \\
\hline Type of Family & 60.7 \\
\hline Nuclear & 35.4 \\
\hline Joint \\
\hline Type of residence \\
\hline Own & 76.4 \\
\hline Rented & 10.8 \\
\hline Hostel & 8.5 \\
\hline Source of Drinking Water \\
\hline Tube well & 17.7 \\
\hline Tap water & 57.4 \\
\hline
\end{tabular}

Table 2: Anthropometric and body composition characteristics of the study population

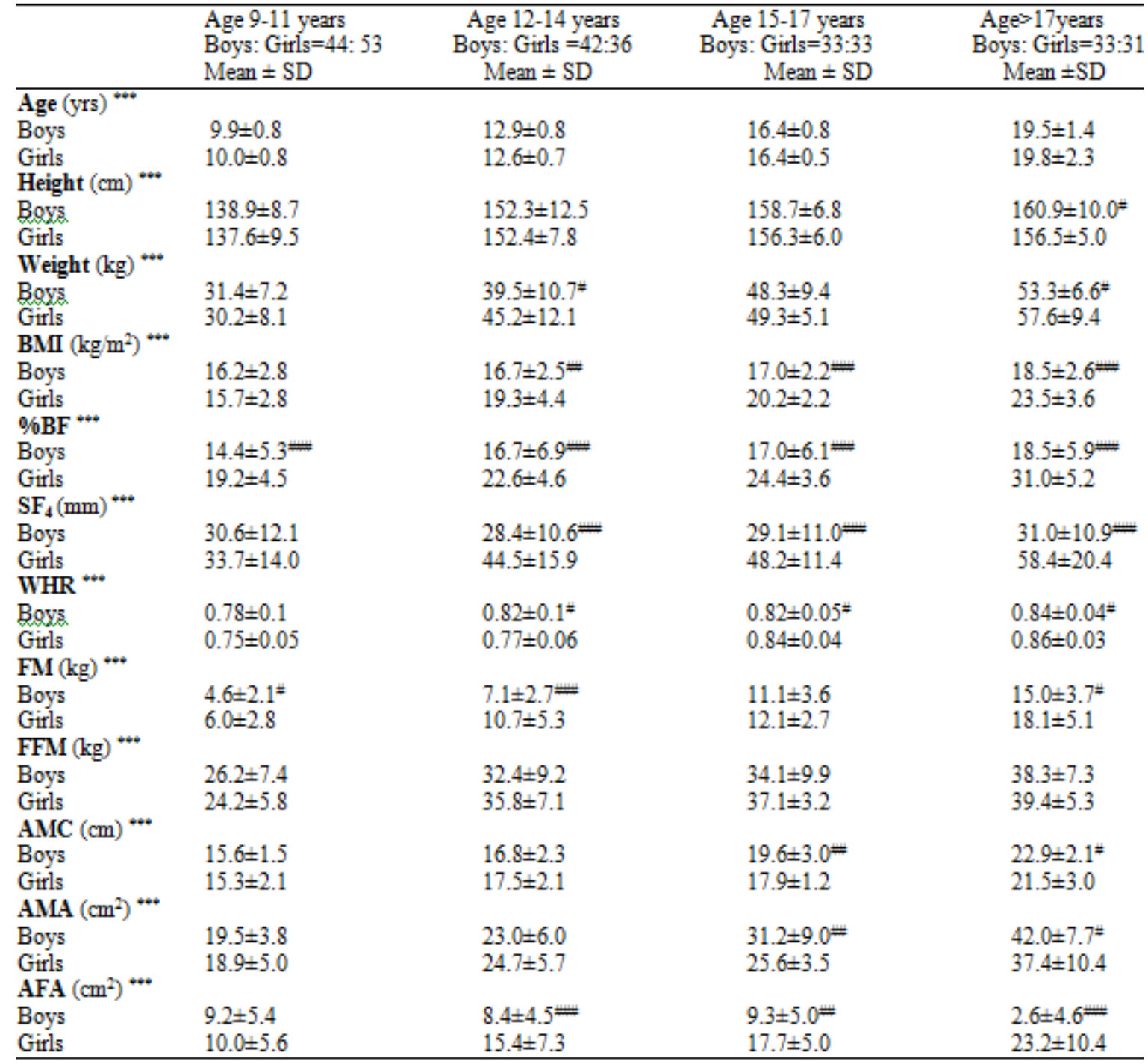

$\mathrm{BMI}=$ body mass index; \%BF $=$ percentage of body fat; $\mathrm{SF}_{4}=$ sum of four skinfolds $($ Biceps + Triceps + Subscapular + Suprailiac); $\mathrm{WHR}=$ waist-hip ratio; $\mathrm{FM}=$ fat mass; $\mathrm{FFM}=$ fat free mass; $\mathrm{AMC}=$ arm muscle circumference; $\mathrm{AMA}=$ arm muscle area; $\mathrm{AFA}=$ arm fat area

ANOVA revealed significant group differences at $* * * \mathrm{p}<0.001$ and t-test revealed significant sex differences at ${ }^{\#} \mathrm{p}<0.05$; \#\# $\mathrm{p}<0.01 ;{ }^{\# \#} \mathrm{p}<0.001$ 


\section{International Journal of Science and Research (IJSR) \\ ISSN (Online): 2319-7064}

Index Copernicus Value (2013): 6.14 | Impact Factor (2015): 6.391

Table 3: Comparison of body composition characteristics by maturity status and sex

\begin{tabular}{lcclc}
\hline & \multicolumn{2}{c}{$\begin{array}{c}\text { Secondary Sexual } \\
\text { Characteristics in Boys }\end{array}$} & \multicolumn{2}{c}{$\begin{array}{c}\text { Beginning of Menarche } \\
\text { in Girls }\end{array}$} \\
& Presence (67) & Absence (85) & Presence (94) & Absence (59) \\
\hline Mean \pm SD & Mean \pm SD & Mean \pm SD & Mean \pm SD \\
\%BF*** & $25.3 \pm 6.6$ & $16.7 \pm 6.8$ & $26.2 \pm 5.6$ & $19.3 \pm 4.4$ \\
FM $^{* * *}$ & $13.0 \pm 4.2$ & $5.8 \pm 2.8$ & $13.9 \pm 5.4$ & $6.1 \pm 2.9$ \\
FFM $^{* * *}$ & $38.1 \pm 6.6$ & $29.2 \pm 8.4$ & $37.5 \pm 5.2$ & $24.6 \pm 6.1$ \\
AMC $^{* * *}$ & $21.1 \pm 3.0$ & $16.3 \pm 2.3$ & $19.1 \pm 2.8$ & $15.4 \pm 2.3$ \\
AMA $^{* * *}$ & $36.1 \pm 9.9$ & $21.1 \pm 6.0$ & $29.5 \pm 9.1$ & $29.3 \pm 5.6$ \\
AFA $^{* * *}$ & $11.1 \pm 5.1$ & $8.7 \pm 4.9$ & $18.8 \pm 8.2$ & $10.1 \pm 5.7$ \\
\hline
\end{tabular}

Sex specific $t$ test revealed significant at $* * * \mathrm{p}<0.001$

Secondary sexual characteristics in Boys= appearance of beard or moustache or voice change

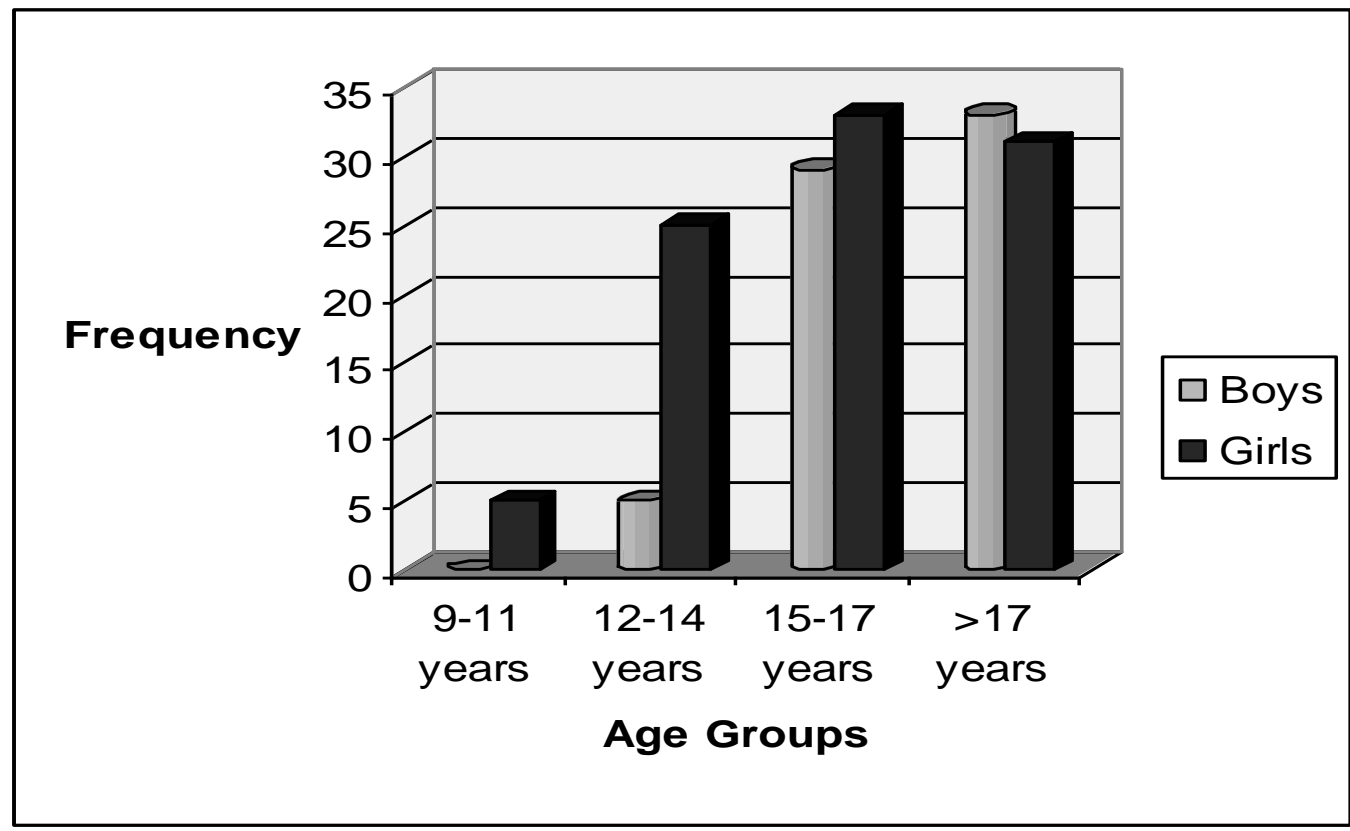

Figure 1: Biological Maturation Status by Age and Sex

Maturation indicators: Girls= on set of menarche; Boys= appearance of moustache or beard or voice change 